\title{
Using Graphene/Polyaniline-Modified Electrodes Enhance the Performance of Two-Chambered Microbial Fuel Cells
}

\author{
Yang Shengke ${ }^{1}$, Wang Yanhua ${ }^{1,2 *}$, Zhou Yang $^{1}$, Li Huihui ${ }^{1}$, Wang Wenke ${ }^{1}$ \\ ${ }^{1}$ The Key Laboratory of Subsurface Hydrology and Ecology in Arid Areas, School of Environmental Science \\ and Engineering, Chang'an University, Xi'an, China \\ ${ }^{2}$ Tourism and Environment College, Shaanxi Normal University, Xi'an, China
}

Received: 7 April 2016

Accepted: 4 December 2016

\begin{abstract}
The development of highly efficient modified electrodes is critical for enhancing the power output of microbial fuel cells (MFCs). In this study, different titanium electrodes were modified with functionalized graphene, polyaniline, and their composite (G/PANI) for use in two-chambered MFCs. The results showed that graphene, polyaniline, and G/PANI modification of the cathode improved the maximum power density of MFCs by $74 \%, 40 \%$, and $126 \%$, respectively, compared with the unmodified control. Among the three materials, G/PANI modification of the anode resulted in the highest open-circuit voltage of MFCs $(0.71 \mathrm{~V})$ and recorded the longest operating time for three consecutive cycles $(110 \mathrm{~h})$. G/PANI was superior to the other two materials in terms of power generation and it also extended the duration of the operating cycle of MFCs. G/PANI modification of both the cathode and anode improved the maximum power density of MFCs to $124.84 \mathrm{~mW} \cdot \mathrm{m}^{-2}$; this value was $24.8 \%$ and $18.9 \%$ higher than those obtained by simple modification of the cathode and the anode, respectively. The duration of the operating cycle of MFCs was also markedly extended to $35 \mathrm{~h}$ after G/PANI modification of both the cathode and anode. SEM results revealed that the increase in power generation of MFCs with G/PANI-modified electrodes could be attributed to the high surface area of electrodes and the large number of bacteria attached to electrodes. These results have demonstrated that the G/PANI composite can be effective materials for modifying electrodes and improving power generation in two-chambered MFCs.
\end{abstract}

Keywords: Graphene, polyaniline, modified electrode, dual-chamber MFC, G/PANI composite

*e-mail: yhwang930@foxmail.com 


\section{Introduction}

Efficient development and utilization of the large amount of biomass energy in wastewater can turn the waste to treasure. Microbial fuel cells (MFCs) are one of the most promising clean energy sources for converting organic fuels - including organic wastes - to electricity by microorganisms [1-3]. MFCs can produce electricity while processing wastewater pollution; thus, they have become a research hotspot in the field of the environment and energy $[2,4]$. The concept of using microorganisms as catalysts in fuel cells was explored in the 1910s [45]. The emergence and development of MFCs provides a new thought for efficiently developing biomass energy in wastewater and implementing wastewater reclamation [6-7]. However, the low power output of MFCs currently restricts their practical applications [7]. Searching for highly effective anode and cathode catalysts, improving reactor architectures, and optimizing operational conditions are crucial strategies for further enhancing the performance of MFCs [8-10].

MFC technology is currently in its infancy and many limitations remain. How to improve reactor power generation is a difficult issue to many researchers. Therefore, it is particularly important to modify the properties of anode and cathode materials in order to reduce the electrode overpotential of anode and cathode in the entire reactor and further optimize the power generation of MFCs [11].

Polyaniline is an excellent conducting polymer characterized by high conductivity, simple synthesis, and low cost. Owing to these advantages, polyaniline is considered to be the most promising conducting polymer [12-14]. However, polyaniline can be problematic for its poor stability; it is also easy to be doped (impure) in the preparation process and difficult to be processed or functionalized [12]. These disadvantages have limited the development of polyaniline.

Graphene is a two-dimensional carbon nanomaterial that forms the basic building block of graphite. Graphene provides a large surface area $\left(2630 \mathrm{~m}^{2} / \mathrm{g}\right)$ and excellent electrical, thermal, and mechanical properties [15-16]. It can be easily prepared from cheap natural graphite [15]. Graphene has been demonstrated to be a promising adsorbent to remove heavy metals from aqueous solution, e.g., uranium [17-18], chromium [19], thorium [20] and antimony [16]. Additionally, graphene has exhibited exciting adsorption abilities for removing hazardous cationic dyes such as methylene blue and safranine $\mathrm{T}$ from contaminated water $[18,21]$. Moreover, graphene hybrid materials have been shown to have potential applications in electronic/spintronic devices [22-23], touch panels [24], gas/biosensors [25-26], and solar cells [27].

The excellent plasticity and stability of graphene can make up the deficiencies of polyaniline. The disadvantages of polyaniline as a conducting polymer, therefore, may be overcome by preparing polyaniline and graphene $(\mathrm{G} /$ PANI) composites [12]. Hou et al. [12] have modified the anode of MFC with G/PANI, which could minimize anode energy loss in the system and significantly increase the power density output of MFC. The power density of MFC with a G/PANI-modified anode is three times larger than that of MFC with unmodified carbon cloth (CC) anode. Thus far, no study has reported on G/PANI modification of both the cathode and anode of MFCs, which is a proposition worth investigating.

In the present study, we prepared electrodes using functionalized graphene, polyaniline, and G/PANI composite and then assessed the performance of the two-chambered MFCs with modified anode and/or cathode. The aim of the study was to improve the deficiencies of anode and cathode of two-chambered MFCs and enhance the power generation and output of the cells. This work has implications for the development and expanded application of MFC technology, and provides a reference for research on wastewater treatment with MFCs.

\section{Experimental}

\section{Preparation of Electrodes}

\section{Preparation of Graphene-Modified Titanium Electrodes}

A phosphate buffer solution was used to formulate a graphene oxide solution $(0.3 \mathrm{~g} / \mathrm{L}, \mathrm{pH}=8)$ as the electrolyte. Cyclic voltammetry was used to reduce graphene oxide by electrodeposition. The scan potential ranged between -1.4 and $+0.6 \mathrm{~V}$; the scan rate was $50 \mathrm{mV} / \mathrm{s}$. One round of scan was recorded as one cycle and the scan included 10 cycles in total. Thereafter, graphene-modified titanium (GTi) electrodes were slowly rinsed with deionized water to remove the residual electrolyte and then dried in a cool and dust-free place before use.

\section{Preparation of Polyaniline-Modified Titanium Electrodes}

A sulfuric acid buffer solution was used to formulate polyaniline electrolyte $(9.3 \mathrm{~g} / \mathrm{L}, \mathrm{pH}=1)$. Electrodeposition was performed using cyclic voltammetry. The scan potential ranged between -0.4 and $+0.9 \mathrm{~V}$; the scan rate was $50 \mathrm{mV} / \mathrm{s}$. One round of scan was recorded as one cycle and the scan included 10 cycles in total. Thereafter, polyaniline-modified titanium (PTi) electrodes were slowly rinsed with deionized water to remove the residual electrolyte and then dried in a cool and dust-free place before use.

\section{Preparation of G/PANI-Modified Titanium Electrodes}

A phosphate buffer solution was used to formulate a mixed solution of graphene and polyaniline $(\mathrm{pH}=6)$. The electrochemical workstation and electrolyte solution were connected, and cyclic voltammetry was performed for electrodeposition. The scan potential ranged between 
-1.4 and $+0.6 \mathrm{~V}$; the scan rate was $50 \mathrm{mV} / \mathrm{s}$. One round of scan was recorded as one cycle and the scan included 10 cycles in total. Thereafter, G/PANI-modified titanium (GPTi) electrodes were slowly rinsed with deionized water to remove the residual electrolyte and then dried in a cool and dust-free place before use.

\section{Comparison of the Preparation Electrode under a Different $p H$ System}

For this paper we tested the electrochemical performance of the preparation electrode under a different $\mathrm{pH}$ system through electrochemical workstation CHI660C. The platinum electrode was taken as the counter electrode, and a saturated calomel electrode as the reference electrode. The scan potential ranged between -0.8 and $+0.8 \mathrm{~V}$; the scan rate was $50 \mathrm{mV} / \mathrm{s}$ (Fig. 1). From graphics, the preparation electrode under the $\mathrm{pH}=6$ system can obviously observe redox peak, and the peak spacing is $0.8 \mathrm{~V}$. Comparing $\mathrm{CV}$ curves on the preparation electrode under $\mathrm{pH}=7$ system, the greater the response peak, the smaller the peak spacing. The preparation electrode under the $\mathrm{pH}=8$ system shows good CV curve peak response. However, its minimum peak spacing is $0.5 \mathrm{~V}$. This shows that the oxidationreduction reversibility of the modified electrode under the system is best. But judging from the response peaks, the charge transfer ability of the modified electrode under $\mathrm{PH}$ $=6$ system is better. General speaking, the $\mathrm{PH}=6$ system is most suitable for the electrochemical preparation of G/PANI-modified electrode.

\section{MFC Construction}

The MFC reactor was comprised of two $700 \mathrm{~mL}$ plastic bottles. A $3 \times 3 \mathrm{~cm}$ opening was made in the body of each bottle to install a proton exchange membrane. Additionally, a small hole was drilled in the lid to replace the nutrient solution and lead the wire. The electrodes were connected to the external resistor $(1,000 \Omega$, unless

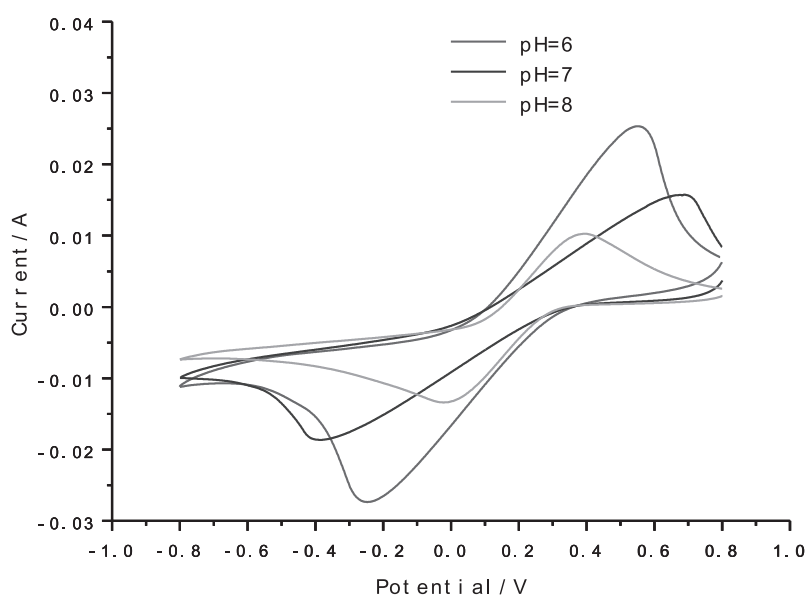

Fig. 1. CV curves on the preparation of electrode under different pH systems.

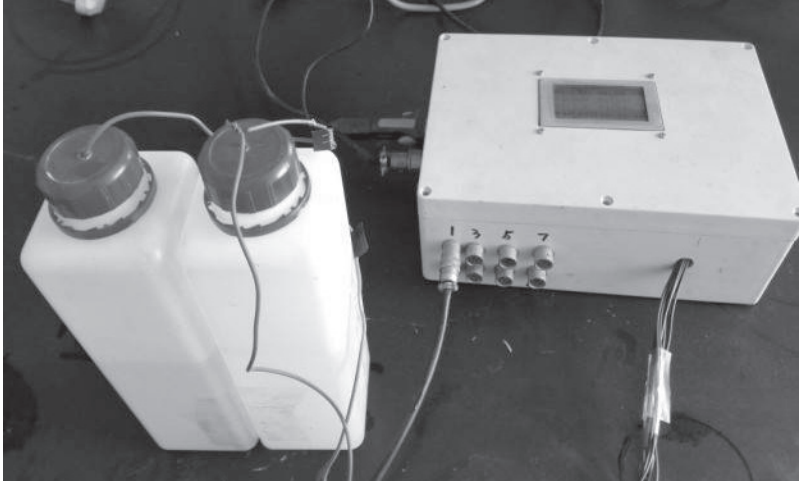

Fig. 2. A photo showing the experimental apparatus of MFCs.

otherwise specified) with titanium wire to form a circuit. Voltage monitoring was performed using an external self-made voltage collector. During voltage measurement, the input port was connected to the external resistor; the output data were transmitted through a USB-to-232 convertor into a computer. Real-time data acquisition was performed at 5-min intervals. The voltage range of the voltage collector was set to $0-2.5 \mathrm{~V}$ and the sampling accuracy was $10-5 \mathrm{~V}$.

\section{MFC Setup and Operation}

A phosphate buffer solution $(0.2 \mathrm{M}, \mathrm{pH}=7)$ was used to formulate $50 \mathrm{mM} \mathrm{K}_{3}\left[\mathrm{Fe}(\mathrm{CN})_{6}\right]$ solution as catholyte. Anode microorganisms were inoculated from domestic wastewater and glucose served as the anode substrate to construct two-chambered MFCs. The anode nutrient solution contained (g/L): $\mathrm{Na}_{2} \mathrm{HPO}_{4}$ (4.089), $\mathrm{NaH}_{2} \mathrm{PO}_{4}$ (2.544), $\mathrm{KCl}(0.13), \mathrm{MgCl} \cdot 6 \mathrm{H}_{2} \mathrm{O}(0.1), \mathrm{CaCl}(0.1), \mathrm{NaCl}$ (2.9), and other essential trace elements; the anolyte volume was $500 \mathrm{~mL}$. The formulated catholyte and anolyte were added into assembled MFC reactors, and each reactor was connected to the data acquisition port of the voltage collector. The voltage collector was then connected to a computer for real-time data acquisition and recording.

At the beginning of the MFC startup, the nutrient solution was replaced once every $48 \mathrm{~h}$. The startup of the MFC reactor was considered to be completed after the output voltage of MFC stabilized between two adjacent cycles. When all MFCs operated stably, one cycle was chosen to record polarization curves and calculate output power density using the galvanostatic method. Polarization curves were generated as follows: After the nutrient solution was replaced, the time interval of MFC to reach a stable state was roughly estimated according to the data of the previous cycle. The cell was then disconnected at the estimated time interval to measure the open circuit voltage. The external resistor was connected and the resistance was changed sequentially in the range of $10 \mathrm{~K} \Omega-100 \Omega$. The measurement interval was $15 \mathrm{~min}$ and the voltage values were recorded after stabilization. 


\section{Electrochemical Characterization}

Electrochemical impedance spectroscopy (EIS) and cyclic voltammograms (CV) were performed on CHI660C (Chenhua, China) in a three-electrode arrangement. SEM (JSM-6700F, Japan) was employed to characterize the surface morphology of the samples. They were prepared following the procedures described elsewhere [28]. All tests were conducted at room temperature.

\section{Results and Discussion}

\section{Effect of Cathode Modification on the Performance of MFCs}

\section{Graphene Modification of Cathode}

Figs 3a-b) show that the maximum power density of the unmodified MFCs (UTi) was $98.41 \mathrm{~mW} \cdot \mathrm{m}^{-2}$; the maximum power density of MFCs with graphene-modified cathode (GTi) was improved by $74.3 \%$, namely $171.70 \mathrm{~mW} \cdot \mathrm{m}^{-2}$. The improvement of power density could be attributed to the increased specific surface area of cathode after medication with a layer of graphene. Meanwhile, graphene material has excellent conductivity and thus could enable the reduction reaction of more electrons and electron acceptors on the cathode surface. The power generation capacity of GTi was therefore markedly improved compared with UTi. This change could accelerate the electron transfer between bacteria and electrodes to optimize the electrode architecture [29-30].

According to the data presented in Figs 3a-b), the internal resistance of UTi and GTi was 534.2 and $441.2 \Omega$, respectively. This result indicates that graphene modification of the cathode could reduce the internal resistance of the reactor. Graphene has high conductivity and thus could significantly reduce the activation energy on the electrode surface of the graphene-modified cathode. Additionally, graphene has high biocompatibility and thus could increase the active surface area of the cathode. Given the above characteristics, the graphene-modified cathode is conducive to increasing the power output of MFCs [15-16, 29].

We recorded voltage output in two MFCs and analyzed the data for one cycle (Fig. 4). The results showed that the output voltage of both GTi and UTi was highest in the first $10 \mathrm{~h}$ of the cycle. This is because after the nutrient solution was replaced, the microorganisms attached on the electrode surface rapidly entered an active phase and consumed a large amount of nutrient solution, resulting in a higher output voltage. Since the graphene-modified electrode had a greater specific surface area and a higher degree of electron reduction, the output voltage of GTi was markedly higher than that of UTi. The maximum output voltage of GTi reached $0.47 \mathrm{~V}$, that is, 1.31 -fold that of UTi. In the following period, the voltage started to decrease and tended to level off. Within one cycle of operation, the operating time of GTi was extended by $11 \mathrm{~h}$ compared with that of UTi.
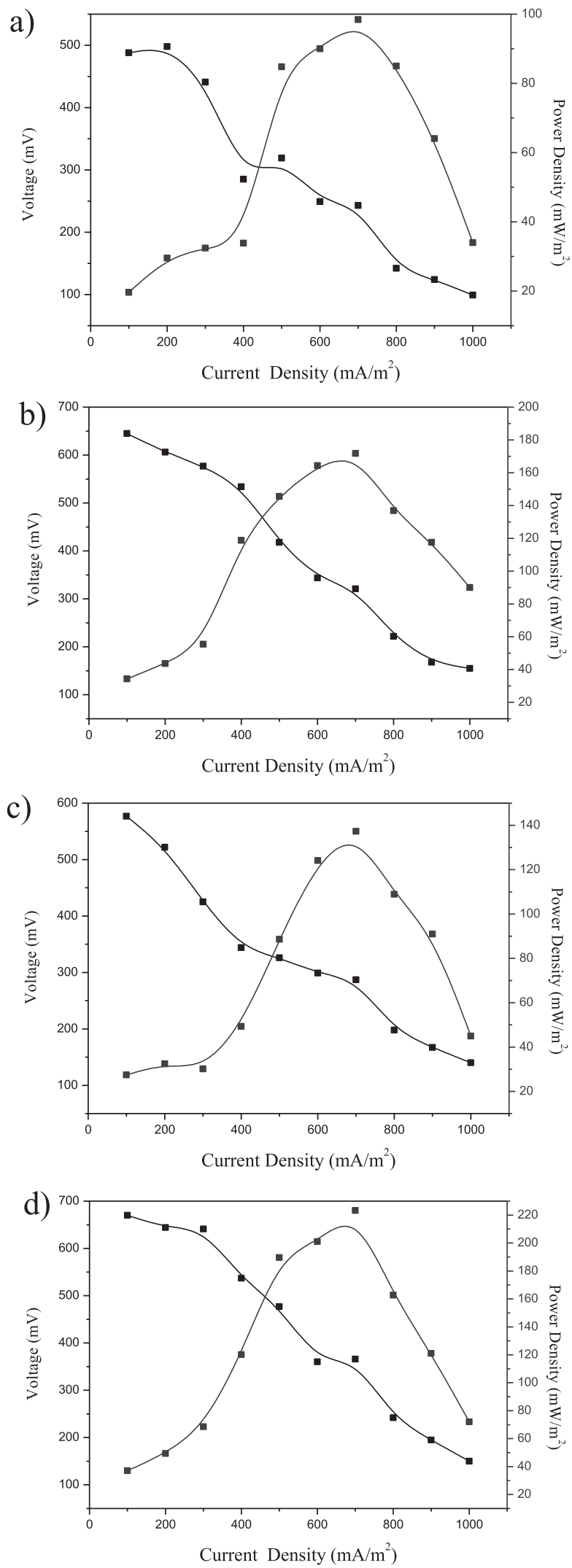

Fig. 3. Polarization curves and power density curves of MFCs with: a) unmodified, b) graphene-modified, c) polyanilinemodified, and d) graphene/polyaniline-modified cathodes. 


\section{Polyaniline Modification of Cathode}

The maximum power density of MFCs with polyaniline-modified cathode (PTi) was $137.28 \mathrm{~mW} \cdot \mathrm{m}^{-2}$ (Fig. 3c), that is, 1.40-fold that of UTi (Fig. 3a). The difference in power density could be attributed to the unique protonic acid doping capacity of polyaniline material. In electrochemical preparation of polyaniline-modified electrode materials, the doping capacity of polyaniline makes it a conducting polymer. This kind of polyaniline has better electrochemical property and higher charge storage capability [12]. We observed voltage output in two MFCs and analyzed the data for one cycle (Fig. 4). Despite similar trajectory of the curves, PTi produced generally higher output voltage than UTi.

Fig. $3 \mathrm{~b}$ ) shows that the maximum power density of GTi was $135.67 \mathrm{~mW} \cdot \mathrm{m}^{2}$, which corresponded to a current density of $750.00 \mathrm{~mA} \cdot \mathrm{m}^{2}$. The maximum power densities of MFCs with UTi and PTi as the cathode were 115.28 and $120.60 \mathrm{~W} \cdot \mathrm{m}^{2}$, respectively; the corresponding current densities were 547.12 and $866.67 \mathrm{~mA} \cdot \mathrm{m}^{2}$, respectively. The maximum power density of GTi was improved by $15.03 \%$ and $11.12 \%$ compared to UTi and PTi, respectively, indicating that graphene medication of cathode significantly improved the power output of MFCs. Graphene increased the active area of the cathode surface, while its high biocompatibility facilitated electron transfer between electrodes and microorganisms. These are critical factors for improving the output power of MFCs [29].

\section{G/PANI Modification of Cathode}

The maximum power density of MFCs with G/PANImodified cathode (GPTi) was $223.26 \mathrm{~mW} \cdot \mathrm{m}^{-2}$ (Fig. 3d), that is, 2.27-fold that of UTi. This result indicates that cathode modification with the composite material could improve power generation of MFCs. We monitored voltage output in two MFCs and analyzed the data for one

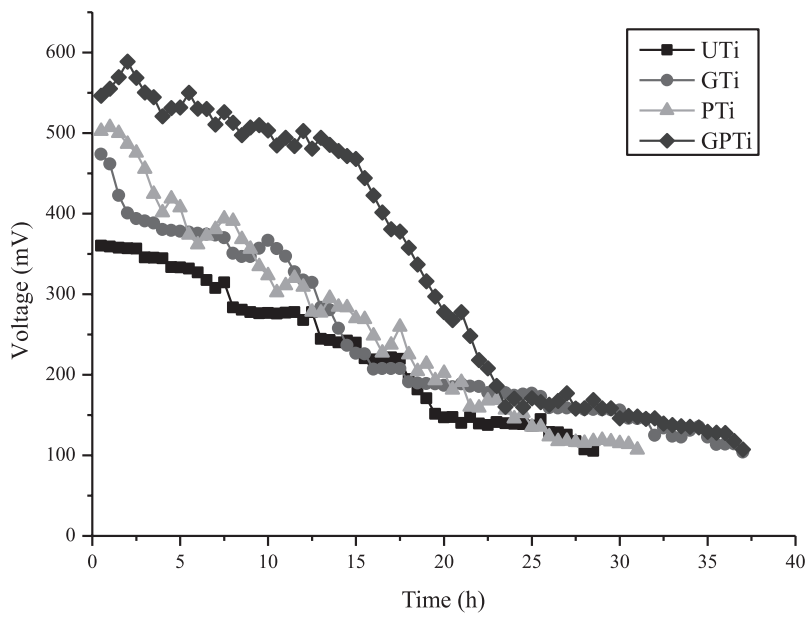

Fig. 4. Output voltage of MFCs with unmodified (UTi), graphene-modified (GTi), polyaniline-modified (PTi), and graphene/polyaniline-modified (GPTi) cathodes for one cycle. cycle (Fig. 4). The results showed that the power generation of GPTi was much higher than that of UTi; the maximum output voltage of the former was 1.63-fold that of the latter. Moreover, GPTi maintained a duration of $20 \mathrm{~h}$ in the high-voltage interval $(>300 \mathrm{mV})$, that is, $10 \mathrm{~h}$ longer than compared to UTi. Thereafter, the output voltage of all MFCs gradually decreased and stabilized at lower levels owing to the decrease of nutrients and the consumption of catholyte $\mathrm{K}_{3}\left[\mathrm{Fe}(\mathrm{CN})_{6}\right]$. In terms of the entire operating cycle, the duration of GPTi (37.5 h) was $10 \mathrm{~h}$ longer than that of UTi $(27 \mathrm{~h})$. This is because the G/PANI composite not only possesses the large specific surface area and high conductivity of graphene, but also inherits the excellent electrochemical property and high charge-storage capability of polyaniline $[12,30]$.

Comparing the data of MFCs assembled with graphene-, polyaniline-, and G/PANI-modified cathodes, we found that the G/PANI-modified electrode was the best cathode material for use in MFCs in terms of power density. The experimental data showed that the maximum power density of GPTi was $30.4 \%$ higher than that of GTi, and 1.62-fold that of PTi.

We plotted the output voltage for three MFCs for three complete cycles (Fig. 5). GPTi was superior to the other two MFCs assembled with graphene- or polyanilinemodified cathode in terms of maximum output voltage, duration in the high-voltage interval, and total duration of the operating cycle. The results suggest that cathode modification with the G/PANI composite, which possesses the large specific surface area and high conductivity of graphene and inherits the electrochemical property of and high charge-storage capacity of polyaniline, can greatly improve the power generation of MFCs.

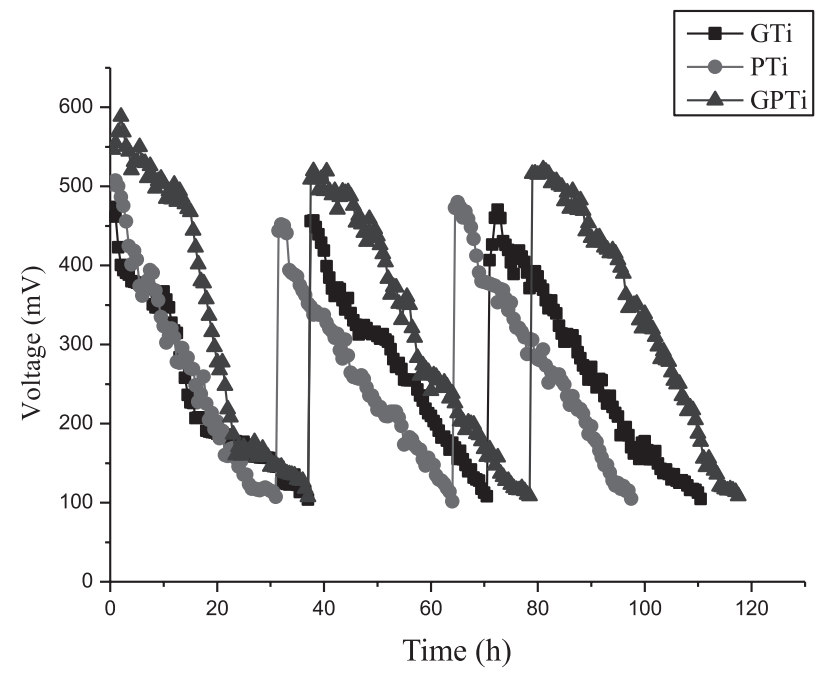

Fig. 5. Output voltage of MFCs with graphene-modified (GTi), polyaniline-modified (PTi), and graphene/polyaniline-modified (GPTi) cathodes. 


\section{Effect of Anode Modifications on MFC Performance}

\section{Graphene Modification of Anode}

Figs $6(\mathrm{a}-\mathrm{b})$ present the polarization curves and power density curves of UTi and GTi. The internal resistance of
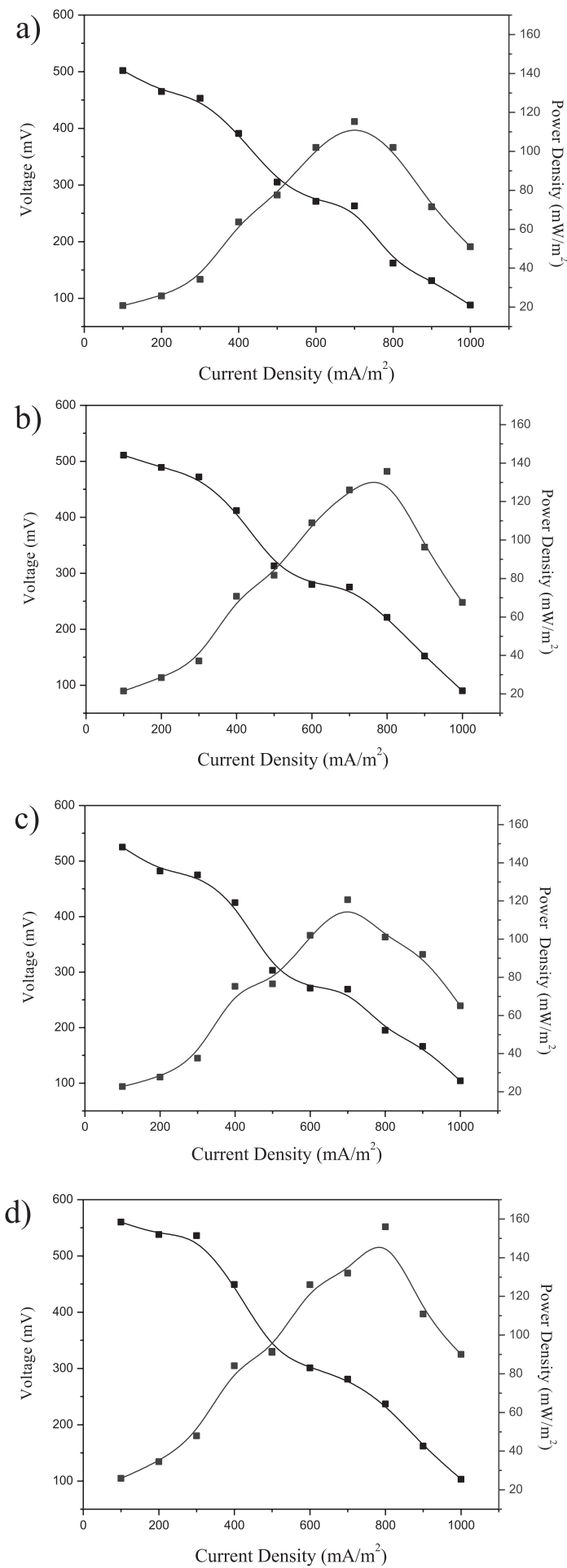

Fig. 6. Polarization curves and power density curves of MFCs with: a) unmodified, b) grapheme-modified, c) polyanilinemodified, and d) graphene/polyaniline-modified anodes.

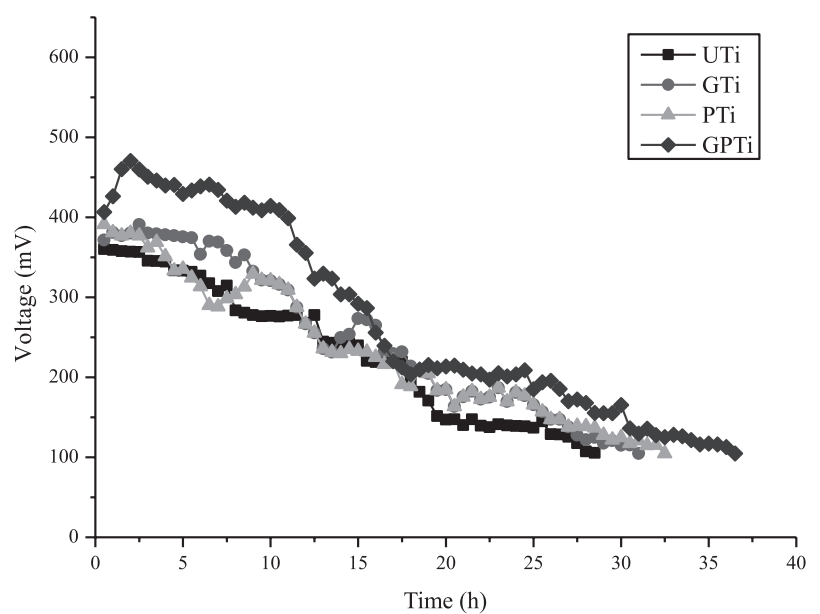

Fig. 7. Output voltage of MFCs with unmodified (UTi), graphene-modified (GTi), polyaniline-modified (PTi) and graphene/polyaniline-modified (GPTi) anodes for one cycle.

MFCs was obtained by polarization curve fitting: 473.48 $\Omega$ for UTi and $400.64 \Omega$ for GTi. The internal resistance was markedly reduced after anode modification with graphene, which could directly affect the power generation of MFCs. The maximum power densities of UTi and GTi were 115.28 and $135.67 \mathrm{~mW} \cdot \mathrm{m}^{-2}$, respectively; the latter was 1.18 -fold that of the former. The possible reason is that graphene has a significant specific surface area; thus, graphene modification greatly improved the specific surface area of the anode and provided more area for the attachment of microorganisms in the anode chamber, further accelerating the generation and transfer of electrons [30-31]. Therefore, MFCs with graphene-modified anodes were improved in power generation compared to the unmodified control.

Next, we monitored voltage output for two MFCs and analyzed the data for one cycle (Fig. 7). GTi performed better than UTi in the high-voltage interval and extended the duration by approximately $5 \mathrm{~h}$. Thereafter, the two MFCs showed similar trends of output voltage curves, but GTi remained slightly higher than UTi. Table 1 shows that GTi produced a higher open circuit voltage $(0.65 \mathrm{~V})$, which was increased by $27 \%$ compared to that of UTi. These results indicate that graphene modification of the anode can improve the power generation of MFCs.

\section{Polyaniline Modification of Anode}

We monitored voltage output for two MFCs and then analyzed the data for one cycle (Fig. 7). The voltage output of PTi showed a rebound trend at around $10 \mathrm{~h}$, which lasted $\sim 5 \mathrm{~h}$. This effectively extended the duration of PTi in the high-voltage interval. In terms of the entire cycle, the output voltage showed no significant difference between PTi and UTi except for the high-voltage interval. This indicates that polyaniline modification of the anode had better effects at the beginning of the operating cycle; as the substrate concentration and microbial activity 
Table 1. Power generation parameters of MFCs with unmodified (UTi) and modified anodes (GTi, PTi, and GPTi).

\begin{tabular}{|c|c|c|c|c|}
\hline MFC & $\begin{array}{c}\text { Maximum power density } \\
\left(\mathrm{mW} \cdot \mathrm{m}^{-2}\right)\end{array}$ & $\begin{array}{c}\text { Maximum current density } \\
\left(\mathrm{mA} \cdot \mathrm{m}^{-2}\right)\end{array}$ & Open-circuit voltage $(\mathrm{V})$ & Internal resistance $(\Omega)$ \\
\hline $\mathrm{UTi}$ & 115.28 & 547.13 & 0.51 & 473.48 \\
\hline $\mathrm{GTi}$ & 135.67 & 750.00 & 0.65 & 400.64 \\
\hline $\mathrm{PTi}$ & 120.60 & 866.67 & 0.58 & 453.00 \\
\hline $\mathrm{GPTi}$ & 156.00 & 874.05 & 0.71 & 322.67 \\
\hline
\end{tabular}

Note: GTi, graphene-modified titanium; PTi, polyaniline-modified titanium; and GPTi, graphene/polyaniline-modified titanium

ecreased over time, the effect of polyaniline modification on the performance of MFCs became less significant [12, 32].

Table 1 shows the open-circuit voltage and internal resistance for two MFCs. The open-circuit voltage and internal resistance of PTi were $0.58 \mathrm{~V}$ and $453 \Omega$, respectively; the values of UTi were $0.51 \mathrm{~V}$ and $473.48 \Omega$, respectively. Polyaniline modification of the anode did not effectively reduce the internal resistance of MFCs, which might be a reason for the minor effect of PTi on the power generation of MFCs.

\section{G/PANI Modification of Anode}

The maximum power density of GPTi $(156.00$ $\left.\mathrm{mW} \cdot \mathrm{m}^{-2}\right)$ was 1.35 -fold that of UTi $\left(115.28 \mathrm{~mW} \cdot \mathrm{m}^{-2}\right.$; Fig. 6d), indicating that G/PANI modification of the anode could improve the performance of MFCs for power generation. We monitored voltage output for two MFCs and then analyzed the data for one cycle (Fig. 7). GPTi showed much higher power generation than UTi; the former was 1.63 -fold the latter in terms of the maximum voltage of MFCs. Moreover, GPTi maintained a duration of $15 \mathrm{~h}$ in the high-voltage interval $(>300 \mathrm{mV})$, which was $5 \mathrm{~h}$ longer compared with UTi. Thereafter, the output voltage of all MFCs gradually decreased and stabilized at lower levels, as the nutrients were reduced and the catholyte $\mathrm{K}_{3}\left[\mathrm{Fe}(\mathrm{CN})_{6}\right]$ was consumed.

With respect to the entire operating cycle, GPTi lasted $37.5 \mathrm{~h}$, that is, $7.5 \mathrm{~h}$ longer than UTi. This is because after G/PANI modification, a layer of G/PANI-doped material gathered on the anode surface and greatly increased the specific surface area of the anode. Meanwhile, polyaniline has good chemical reactivity, which directly increased the number and density of active reaction sites on the anode surface. In electrochemistry, the anode overpotential is a common factor limiting the performance of MFCs for power generation [32-33]. During the reaction of G/PANImodified anode the anode overpotential was reduced, thereby improving the power generation of MFCs.

Table 1 lists the power generation parameters of UPTi and GTi. When the external resistor was disconnected, the open-circuit voltage of GPTi reached $0.71 \mathrm{~V}$; this value was improved by $\sim 40 \%$ compared with that of UTi. The internal resistance of GPTi $(322.67 \Omega)$ was also lower than that of UTi, indicating that G/PANI modification of the anode reduced the internal resistance of the entire MFC system. Since internal resistance is another important factor limiting the performance of MFCs for power generation $[31,34]$, a reduction in internal resistance means an improvement in power generation of MFCs.

Comparing the data of MFCs assembled with graphene-, polyaniline-, and G/PANI-modified anodes, we found that the G/PANI-modified electrode was the best anode material for use in MFCs in terms of power density. The maximum power density of GPTi was improved by 1.16-fold compared with that of GTi, and 30\% higher than that of PTi.

We plotted the output voltage for three MFCs for three complete cycles (Fig. 8). GPTi was superior to the other two MFCs with GTi and PTi in terms of maximum output voltage, duration of the high-voltage interval, and duration of the entire operating cycle. Table 1 shows the power generation parameters for three MFCs. GPTi showed better performance for power generation than GTi, despite the same internal resistance. This shows that the incorporation of polyaniline into graphene effectively improved the electrode material. The excellent electrochemical activity and high conductivity of polyaniline were inherited by the G/PANI composite.

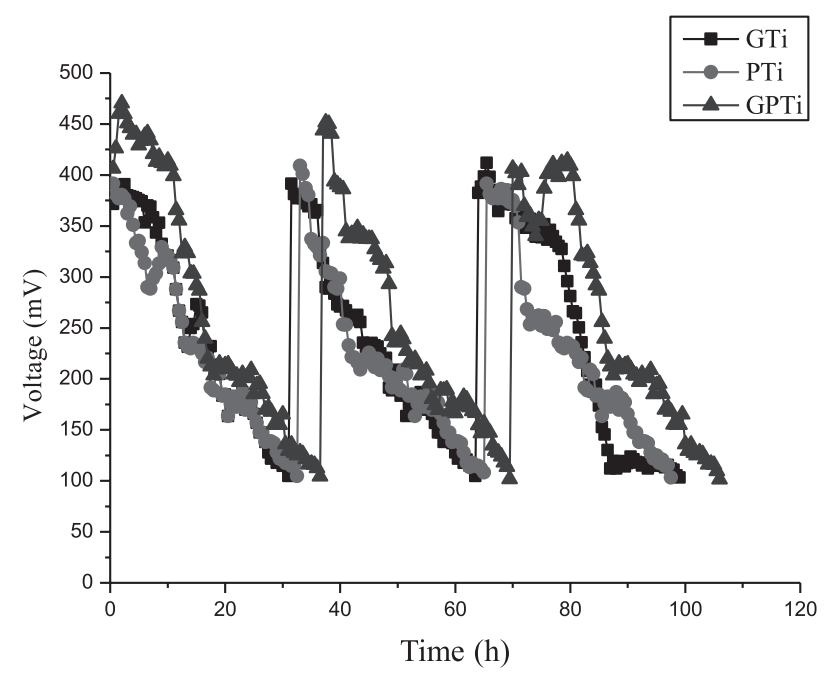

Fig. 8. Output voltage of MFCs with graphene-modified (GTi), polyaniline-modified (PTi), and graphene/polyaniline-modified anodes (GPTi). 


\section{Effect of Cathode and Anode Modification on the Performance of MFCs \\ G/PANI Modification of Cathode and Anode}

In this experiment, we tested three MFCs assembled with modified anode and cathode (reactor A), modified cathode (reactor B), and modified anode (reactor C). All the electrodes were modified electrochemically with G/ PANI. When all MFCs operated stably, we chose one cycle to perform a steady-state discharge test. The polarization curves were generated and the output power density was calculated (Fig. 9).

The maximum power density of reactor $\mathrm{A}$ was the highest among the three reactors, namely $124.84 \mathrm{~mW} \cdot \mathrm{m}^{-2}$. The results of reactors $\mathrm{B}$ and $\mathrm{C}$ were close, at 100.04 and $105.00 \mathrm{~mW} \cdot \mathrm{m}^{-2}$, respectively. Reactor A was improved by $24.8 \%$ and $18.9 \%$ compared with reactors $\mathrm{B}$ and $\mathrm{C}$, respectively, indicating that G/PANI modification of both the anode and cathode was most effective in improving the performance of MFCs for power generation. On balance, the performance of MFCs was lower compared with the results of MFCs in Sections 3.2 and 3.1. This is because the electrodes used in this experiment comprised titanium sheet only, while those in the previous sections comprised titanium sheet and stainless steel wire mesh. Wire mesh had a larger surface area and higher surface reactivity than the titanium sheet, accounting for higher power generation of MFCs.

The internal resistance of MFCs was obtained by polarization curve fitting. Reactor $\mathrm{A}$ had an internal resistance of $300 \Omega$; reactors $\mathrm{B}$ and $\mathrm{C}$ had the same internal resistance of $500 \Omega$. This result indicates that the use of both the G/PANI-modified anode and cathode in MFCs could effectively reduce the internal resistance of the reactor. This also explained the superiority of reactor A to reactors $\mathrm{B}$ and $\mathrm{C}$ in terms of power density.

After the completion of MFC startup, we replaced the nutrient solution, observed the three MFCs for 2-3 weeks,

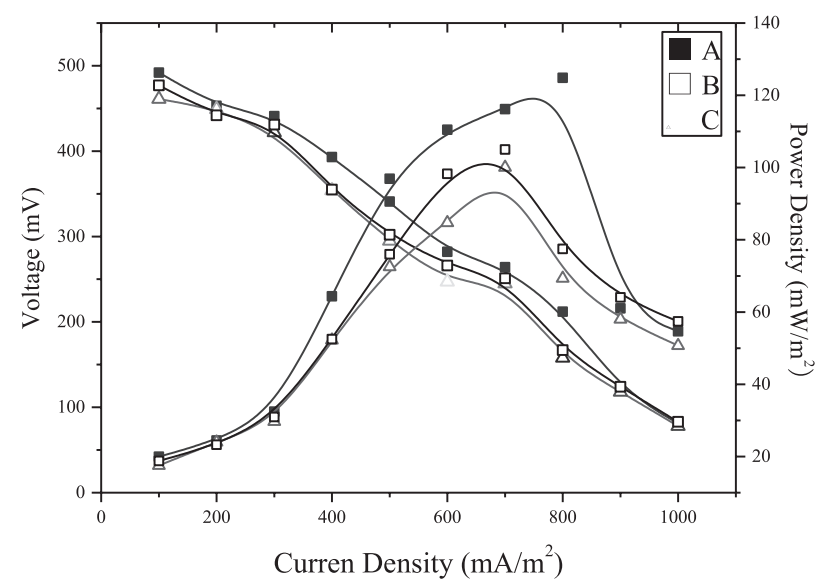

Fig. 9. Polarization curves and power density curves of MFCs with graphene/polyaniline (G/PANI)-modified anode and cathode (A), G/PANI-modified cathode (B), and G/PANI-modified anode (C) for one cycle.

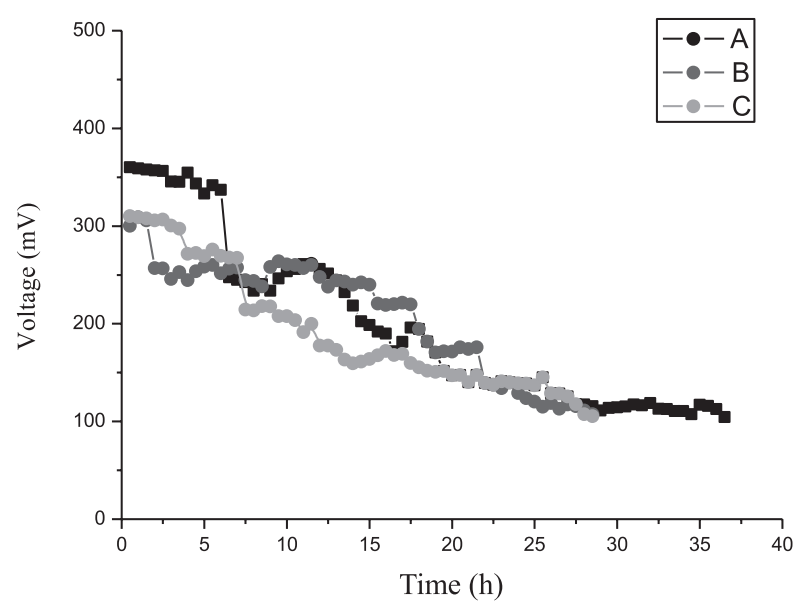

Fig. 10. Output voltage of MFCs with graphene/polyaniline (G/ PANI)-modified anode and cathode (A), G/PANI-modified cathode (B), and G/PANI-modified anode (C) for one cycle.

and then analyzed data for one cycle (Fig. 10). After the replacement of nutrient solution, the output voltage of MFCs rapidly increased and peaked at $360 \mathrm{mV}$ (reactor A), $305 \mathrm{mV}$ (reactor B), and $300 \mathrm{mV}$ (reactor C). Thereafter, the voltage rapidly dropped to relatively stable levels at 342,261 , and $256 \mathrm{mV}$, respectively. Finally, the power generation of the entire reactor decreased and the output voltage showed a downward trend. This process agrees with the growth pattern of microorganisms in the anode chamber [7, 35], suggesting that the growth of output voltage was coincident with the growth of microbial number. With respect to the entire operating cycle, the duration of reactor $\mathrm{A}(36.6 \mathrm{~h})$ was extended by 8.3 and $9.0 \mathrm{~h}$, respectively, compared with those of reactors $\mathrm{B}$ and $\mathrm{C}$.

\section{Electrochemical Analysis}

To further assess the performance of MFCs, we performed cyclic voltammetry (CV) analysis after the three

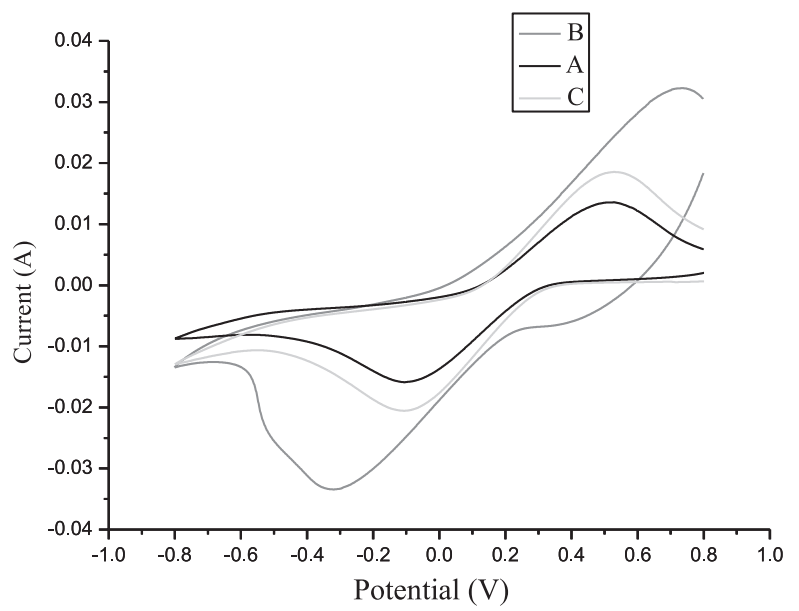

Fig. 11. CV curves of MFCs with graphene/polyaniline (G/ PANI)-modified anode and cathode (A), G/PANI-modified cathode (B), and G/PANI-modified anode (C). 


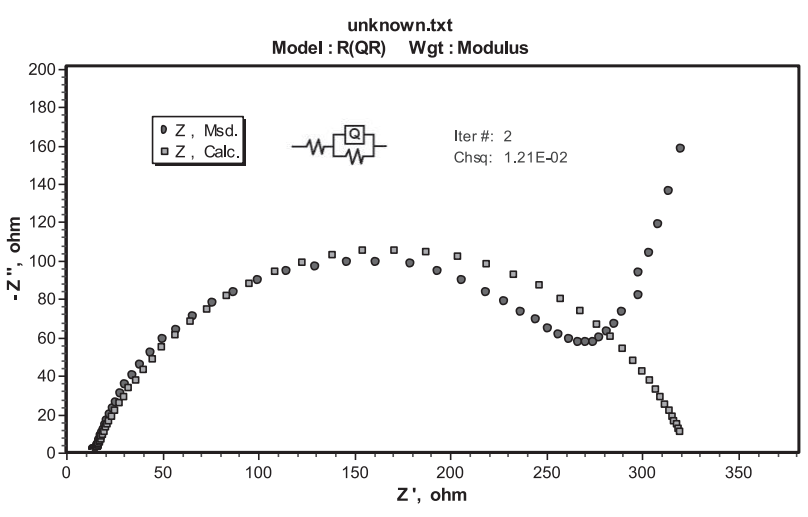

Fig. 12. Impedance and fitting curve of MFCs with graphene/ polyaniline-modified anode and cathode.

MFC reactors operated stably. The analysis was conducted on the CHI66C electrochemical workstation. A saturated calomel electrode served as the reference electrode. The scan potential ranged between -0.9 and $+0.9 \mathrm{~V}$. The scan rate was set to $0.05 \mathrm{v} / \mathrm{s}$. Fig. 11 shows the presence of obvious redox peaks in all three MFCs. The CV curves of reactors $\mathrm{A}$ and $\mathrm{C}$ were similar: the peak potential was -0.1 and $+0.5 \mathrm{v}$, making the peak potential difference $\sim 0.6 \mathrm{v}$. For reactor B, the peak potential was -0.3 and $+0.8 \mathrm{v}$, making the peak potential difference was $1.1 \mathrm{v}$. These results indicate that reactors $\mathrm{A}$ and $\mathrm{C}$ had higher redox reversibility than reactor B.

a)

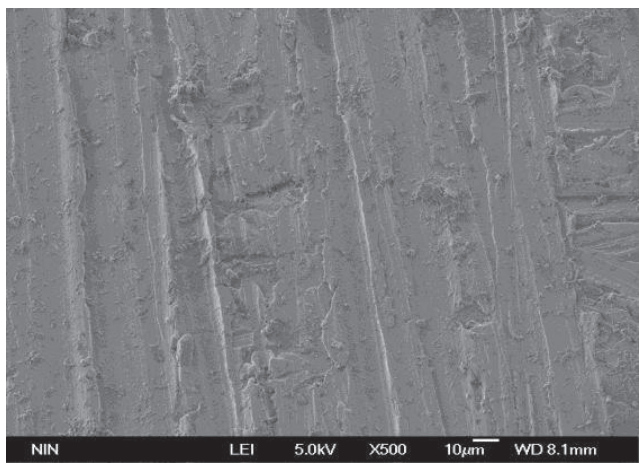

c)

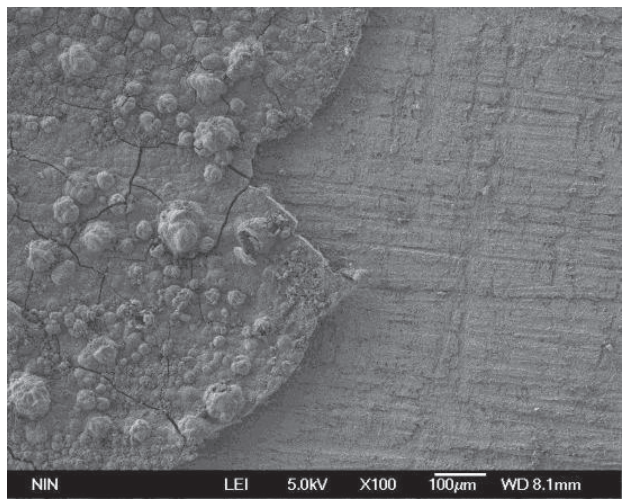

Fig. 12 depicts the impedance and fitting curve of MFCs with G/PANI-modified anode and cathode. The degree of fitting was good between the $\mathrm{AC}$ impedance curve measured by CHI660C and the fitting curve of the equivalent circuit, and there was an obvious capacitive arc. The resistance was $\sim 15 \Omega$, indicating good electrochemical activity of the reactors.

\section{SEM Study}

After discharge, the surface morphologies of each electrode were immediately examined by SEM. Fig. 13 shows the surface morphologies of titanium electrodes after the operation of MFCs. Regarding the anode after the operation of MFCs, it was claimed that the SEM image illustrated that the surface morphologies of unmodified and modified titanium electrodes after operation. Fig. 13b) shows some graphene/polyaniline-modified dark spots. A small number of flocculent microorganisms adhered to the unmodified titanium electrode (a) and a significant number of flocculent and filamentous microorganisms adhered to the G/PANI-modified titanium electrode (b). The anode product has adhered to the electrode surface and led to the electrode surface change. Moreover, the change of the anode surface after modification was more pronounced and more microorganisms gathered. It was conducive to the growth of microorganisms and the electrode surface reaction was faster. This may be due to the modification of G/PANI electrode material increasing

b)

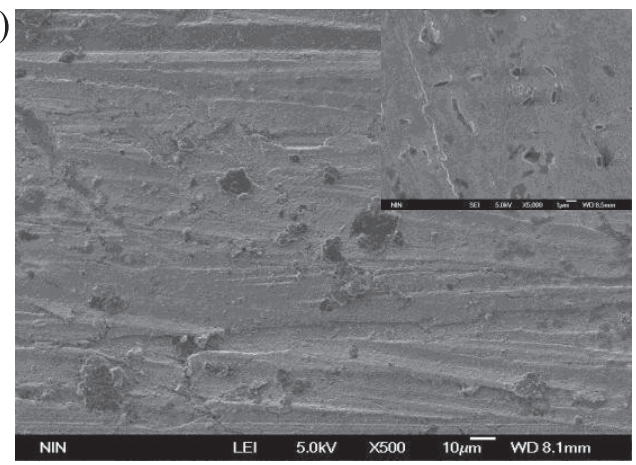

d)

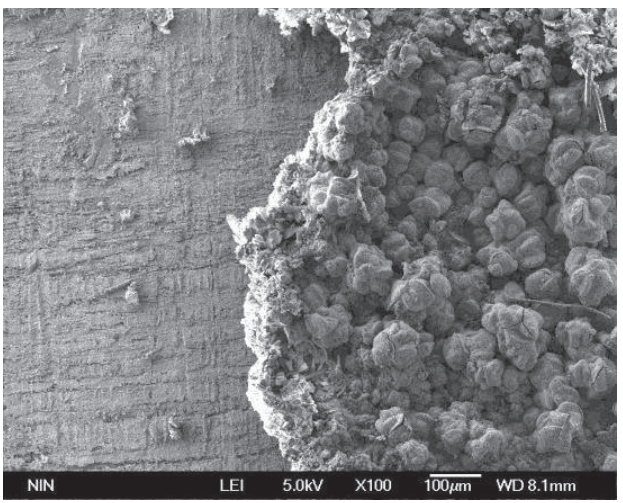

Fig. 13. SEM images showing the surface morphologies of unmodified and modified titanium electrodes after operation (a-b: anode, c-d: cathode) of MFCs.

a) Unmodified titanium electrode (UTi), b) Graphene/polyaniline-modified anodes (GPTi), c) UTi, d) GPTi. 


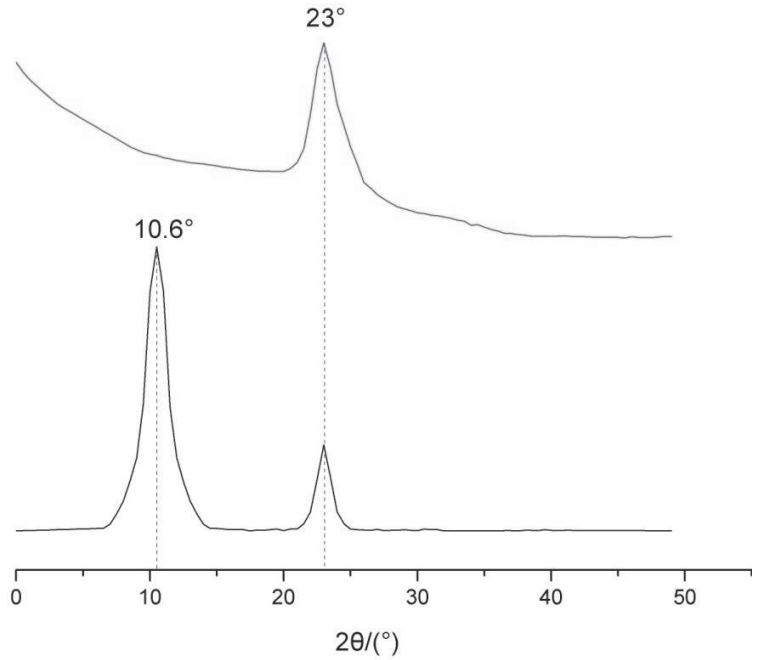

Fig. 14. XRD patterns.

the roughness of the electrode surface area, thereby improving the activity of the cell system. Regarding the cathode after the operation of MFCs: a very small amount of white attachment appealed on the unmodified titanium electrode (c) and a significant amount of white attachment adhered to the G/PANI-modified titanium electrode (d). A lot of sediment attached to the surface of electrodes should come from the reduction reaction product of the cathode. The electron microscopy phenomenon of the modified electrodes means greater amount of product, verifying the intense current response characteristics. It shows that the modified cathode G/PANI materials could provide more reactive point and the reaction rate on the cathode a greater increase. Comparing the anode and cathode after operation, we observed great morphological differences. The anode was attached with a markedly higher number of bacteria (mostly rods) than those of the cathode. Moreover, the titanium electrode of the anode was not coated with a porous structure after operation. This further proves that the proposed method is effective for forming G/PANI hybrid coating on titanium electrode in this study.

\section{XRD Study}

Fig. 14 shows the XRD pattern. The characteristic peak at $23^{\circ}$ was the characteristic diffraction peak of grapheme and the sharp diffraction peaks at $10.6^{\circ}$ were the characteristic peaks of graphene oxide. When graphene oxide was reduced, the diffraction peak at $10.6^{\circ}$ diminished and eventually disappeared. However, the diffraction peak at $23^{\circ}$ had become higher, demonstrating that graphene oxide is reduced to graphene.

\section{Conclusions}

This study employed a facile and environmentally friendly method to modify the anode and cathode of MFCs with G/PANI composite, and achieved enhanced
MFC performance with regard to power generation. Our experimental results prove that the proposed method is simple and reliable for the fabrication of high-performance MFCs. Using G/PANI composites simultaneously modified the anode and cathode of MFCs while increasing the specific surface area of the electrode and the electrochemical activity of the electrode surface. The anode is not advantageous only to the aggregation and growth of the microorganism, it is advantageous for the reaction of potassium ferricyanide in the cathode. This promoted electron recovery and made the entire electrode better. These results provide significant prospects for developing low-cost and effective MFC anodes and cathodes. Further studies are necessary to assess whether the proposed method is applicable to large-scale MFCs from a practical perspective.

\section{Acknowledgements}

The study was supported by the National Natural Science Foundation of China (Nos. 41372259 and 41672224) and the Fundamental Research Funds for the Central Universitis (Nos. 310829153311 and GK201703052).

\section{References}

1. CAO X.X., HUANG X., LIANG P., BOON N., FAN M.Z., LIN Z., ZHANG X.Y. Energy \& Environmental Science, 2 (5), 498, 2009.

2. ZHANG Y.J., LI Y.F., LIU C.Y., WANG Y.X., LI L., WANG Z.R., DONG Y.X. Chinese Journal of Environmental Science, 33 (7), 2427, 2012 [In Chinese].

3. YANG H., LIU Z.H., LI X.M, YANG Q., FANG L., HUANG H.J., ZENG G.M., LI S. Chinese Journal of Environmental Science, 33 (1), 216, 2012 [In Chinese].

4. DU Z.W., LI H.R., GU T.Y. Biotechnology Advances, 25 (5), 464, 2007.

5. BULLEN R.A., ARNOT T.C., LAKEMAN J.B., WALSH F.C. Biosensors and Bioelectronics, 21 (11), 2015, 2006.

6. HOU J.X., LIU Z.L., LI Y.X., YANG S.Q, ZHOU Y. Bioprocess Biosyst Eng., 38, 881, 2015.

7. LIU J., QIAO Y., GUO C.X., LIM S., SONG H., LI C.M. Bioresource Technol. 114, 275, 2012.

8. CHEN S., HE G., LIU Q., HARNISCH F., ZHOU Y., CHEN Y., HANIF M., WANG S., PENG X., HOU H. Energy Environ. Sci., 5 (12), 9769, 2012.

9. DEEKE A., SLEUTELS T.H., HAMELERS H.V., BUISMAN C.J. Environ. Sci. Technol., 46 (6), 3554, 2012.

10. YONG Y.C., DONG X.C., CHAN-PARK M.B., SONG H., CHEN P., ACS Nano, 6 (3), 2394, 2012.

11. TANG J.H., CHEN S.S., YUAN Y., CAI X.X., ZHOU S.G. Biosensors and Bioelectronics, 71, 387, 2015.

12. HOU J.X., LIU Z.L., ZHANG P.Y. J. Power Sources, 224, 139, 2013.

13. QIAO Y., LI C.M., BAO S.J., BAO Q.L. J. Power Sources, 170, 79, 2007.

14. LV Z.S., XIE D.H., YUE X.J., FENG C.H., WEI C.H. J. Power Sources, 210, 26, 2012. 
15. GUO J., WANG R., TJIU W.W., PAN J.S., LIU T.X. J. Hazard. Mater., 225-226, 63, 2012.

16. DONG S.X., DOU X.M., MOHAN D., CHARLES P., LUO J.M. Chem. Eng. J., 270, 205, 2015.

17. LI Z.J., CHEN F., YUAN L.Y., LIU Y.L, ZHAO Y.L., CHAI Z.F., SHI W.Q. Chem. Eng. J., 210, 539, 2012.

18. LI Z.J., WANG L., YUAN L.Y., XIAO C.L., MEI L., ZHENG L.R., ZHANG J., YANG J.H., ZHAO Y.L., ZHU Z.T., CHAI Z.F., SHI W.Q. J. Hazard. Mater., 290, 26, 2015.

19. JABEEN H., CHANDRA V., JUNG S., LEE J.W., KIM K.S., KIM S.B. Nanoscale, 3, 3583, 2011.

20. BAI Z.Q., LI Z.J., WANG C.Z., YUAN L.Y., LIU Z.R., ZHANG J., ZHENG L.R., ZHAO Y.L., CHAI Z.F., SHI W.Q. RSC Adv., 4, 3340, 2014.

21. LIU J., LIU G., LIU W. Chem. Eng. J., 257, 299, 2014.

22. EDA G., CHHOWALLA M. Nano Lett., 9, 814, 2009.

23. NOORDEN R.V. Nature, 469, 14, 2011.

24. BAE S., KIM H., LEE Y., XU X., PARK J.S., ZHENG Y., BALAKRISHNAN J., LEI T., KIM H.R., SONG Y.I., KIM Y.J., KIM K.S., OZYILMAZ B., AHN J.H., HONG B.H., IIJIMA S. Nanotechnol, 5, 574, 2010.

25. MYUNG S., SOLANKI A., KIM C., PARK J., KIM K.S., LEE K.B. Adv. Mater., 23, 2221, 2011.
26. SCHEDIN F., GEIM A.K., MOROZOV S.V., HILL E.W., BLAKE P., KATSNELSON M.I., NOVOSELOV K.S. Nat. Mater., 6, 652, 2007.

27. LI S.S., TU K.H., LIN C.C., CHEN C.W., CHHOWALLA M. ACS Nano, 4, 3169, 2010.

28. PARK D.H., ZEIKUS J.G. Biotechnol. Bioeng., 81, 348, 2003.

29. LIU Z.L., ZHOU Y., HOU J.X., YANG S.Q., LI J.Y., LI Y.X. Technology of water treatment, 40 (40), 16, 2014 [In Chinese].

30. ZHANG Y.Z., MO G.Q., LI X.W., ZHANG W.D., ZHANG J.Q., YE J.S., HUANG X.D., YU C.Z. J. Power Sources, 196, 5402, 2011.

31. LI X., DAMIENA J., LUO J.Y. J. Power Sources, 208 (196), 5402, 2012.

32. GUO W., PI Y.Q., SONG H., TANG W., SUN J.H. Colloids and Surfaces A, 415, 105, 2012.

33. SONG H., GUO W., LIU M.L., SUN J.H. Water Science \& Technology, 68 (12), 2599, 2013.

34. YANG J.P., WANG J.Q., CHEN S.H., CHEN C., YANG F. Chinese Journal of Environmental Engineering, 7 (5), 1837, 2013 [In Chinese].

35. LI H., NI J. Bioresource Technol., 102 (3), 2731, 2011. 
